\title{
On the potential of Bacillus aryabhattai KMT-4 against Meloidogyne javanica
}

\author{
Sonam Antil ${ }^{1} \mathbb{D}$, Rakesh Kumar ${ }^{1 *}$ (D, D. V. Pathak ${ }^{1}$, Anil Kumar ${ }^{2}$, Anil Panwar ${ }^{3}$, Anju Kumari ${ }^{4}$ and Vinod Kumar ${ }^{2}$
}

\begin{abstract}
Background: Nematodes (Meloidogyne spp.) are a major reason behind the global crop yield reduction. The bacterial strain KMT-4 was isolated from nematode-affected tomato (Solanum lycopersicum) rhizosphere at research farms, Hisar, India, and screened for its biocontrol potential against root-knot nematode Meloidogyne javanica as well as checked for its effect on plant growth and yield.

Results: The bacterium KMT-4 was identified as Bacillus aryabhattai based on phenotypic characters and 16S rRNA sequence analysis. During in vitro studies, hatching and mortality of $M$. javanica were significantly affected due to the antagonistic behavior exhibited by the bacterium. In addition to this, KMT-4 also displayed various direct as well as indirect plant growth-promoting attributes like siderophore production, growth hormone (IAA) production, ammonia excretion, hydrogen cyanide production, and chitinase activity. A pot house experiment conducted on brinjal resulted in nearly $73 \%$ reduction in eggs, while $80 \%$ reduction in galls in the plant root compared to the untreated and chemically treated plants. The final nematode population also reduced significantly in KMT-4 treatment. It was $1141.6 \mathrm{~J} 2 / 200 \mathrm{cc}$ soil in control and reduced to $108 \mathrm{~J} 2 / 200 \mathrm{cc}$ soil inoculated with KMT-4. Similar results were obtained in field experiments on brinjal and cucumber conducted in years 2018 and 2019, respectively. Also, a notable enhancement in the plant growth was observed in both pot house experiment and field trials.

Conclusion: The possession of nematicidal activity along with plant growth-promoting properties in B. aryabhattai KMT-4 warrants its employment as a potent biological control agent against M. javanica and a promising substitute of chemical nematicides.
\end{abstract}

Keywords: Root-knot nematodes, Meloidogyne javanica, Bacillus aryabhattai, Rhizosphere, Plant growth, Biological control

\section{Background}

Plant-parasitic nematodes or phytonematodes are the major threat to fruit and vegetable farmers across the world whereby root-knot nematodes (Meloidogyne spp.) dominate in numbers. These are parasitic microscopic roundworms that feed on plants and cause deleterious effects. The infection is caused by the second stage juveniles (J2) of root-knot nematodes that further results in knots or swellings in plant roots. On the anterior end, they have a protruded stylet which acts like a hypodermic needle

\footnotetext{
* Correspondence: sehrawatrk@hau.ac.in

${ }^{1}$ Department of Microbiology, College of Basic Sciences and Humanities, CCS Haryana Agricultural University, Hisar, Haryana 125004, India Full list of author information is available at the end of the article
}

used to puncture and penetrate the cells of the target plant. These organisms are universally distributed with a wide range of hosts. The most important feature of these parasitic agents is their irregular distribution in crops due to which they infect in patches and can differ in size, number, and shapes (Zareena and Das, 2014).

Nematode infection is the major cause of growth and yield reduction under protected cultivation. Major fruit and vegetable crops like tomato, brinjal, cucumber, and okra also face crop losses due to such invaders (Sahebani and Hadavi, 2008). Brinjal (Solanum melongena L.) is a nightshade species and is the second most essential fruit crop of the family Solanaceae after tomatoes. Global production of brinjal is nearly 50 million tons annually 
with a net value of more than US\$10 billion (FAO, 2014). In India, the crop is majorly cultivated in Orissa, Bihar, West Bengal, Maharashtra, Uttar Pradesh, Karnataka, and Andhra Pradesh. This crop is highly prone to infection by the root-knot nematodes, particularly of the genus Meloidogyne (M. incognita and M. javanica). Nematode damage causes reduction in plant health and growth which results in decline in yield, quality, and decreased resistance to different biotic and abiotic stress. Cucumber (Cucumis sativus L.) is highly susceptible to Meloidogyne infection, which attacks its roots and induces formation of giant cells (Zhang et al., 2014). A clear information on how this pathogen affects cucumber roots, the changes in host gene expression associated with such attacks, is not clear.

Various effective chemical nematicides have been tested against nematodes but not considered as longterm solutions because of concerns like health and environmental hazards, exposure risks, residue persistence, and expensiveness. To combat such harmful effects and due to awareness among end users, an effective but ecofriendly trend is being opted, i.e., using bio-agents to control phytonematodes. Many rhizospheric bacteria have already been reported to act as biological control agents against these phytonematodes because of their capacity to produce iron chelating siderophores; metabolites like antibiotics; wall-degrading enzymes such as chitinase, which helps in degrading chitinaceous egg wall of nematodes; hydrogen cyanide, etc. Also, they compete with pathogenic organisms for specific niches as well as nutrients and have the capacity to elicit systemic resistance in host plants. Bacillus thuringiensis has been reported to suppress the population of $M$. incognita and $M$. javanica by producing nematicidal biomolecules (Mohammed et al., 2008). Other Bacillus species like $B$. cereus and B. amyloliquefaciens also proved to be good biocontrol agents (Jamal et al., 2017). However, there is limited information available on such biocontrol agents also acting as plant growth promoters alongside.

The objectives of this investigation were to (i) isolate and identify KMT-4 by a combination of morphological and molecular biology methods, (ii) assess the antagonistic behavior against $M$. javanica eggs and juveniles in vitro, (iii) evaluate the biocontrol potential of KMT-4 toward $M$. javanica in pot and field experiments, and (iv) determine the effect of KMT-4 on plant growth and yield. This study will provide basic knowledge about the application of KMT-4 as a potent biocontrol agent which not only shows antagonism against phytopathogenic root-knot nematodes but also promotes plant growth.

\section{Methods}

\section{Isolation of the bacterial strain}

Bacterial strain KMT-4 was isolated from the nematodeinfected tomato rhizosphere at a screen house of
Department of Nematology, Hisar, Haryana, India $\left(29^{\circ} 08^{\prime}\right.$ 29.7" N, 75²'14.0" E), using serial dilution technique. The bacterium was selected through various biochemical and antagonistic tests against $M$. javanica. It was cultured in King's B medium-peptone $20 \mathrm{~g} / \mathrm{l}$, glycerol $10 \mathrm{ml} / \mathrm{l}$, $\mathrm{K}_{2} \mathrm{HPO}_{4} 1.5 \mathrm{~g} / \mathrm{l}, \mathrm{MgSO}_{4} 1.5 \mathrm{~g} / \mathrm{l}$, glucose $1 \mathrm{~g} / \mathrm{l}, \mathrm{NaCl} 3-5 \mathrm{~g} / \mathrm{l}$, $\mathrm{pH} 7$ (King et al., 1954) at $30^{\circ} \mathrm{C}$ with shaking at $300 \mathrm{rpm}$ till $48 \mathrm{~h}$ for further studies. The bacterial cells were adjusted to obtain $10^{8} \mathrm{CFU} / \mathrm{ml}$ with sterile distilled water.

\section{Identification of the bacterial strain KMT-4}

KMT-4 was subjected to various morphological studies and Gram staining. The $16 \mathrm{~S}$ rRNA sequence analysis was done for the identification of the bacterial strain. Genomic DNA was extracted according to the manufacturer's protocol of the Genomic DNA isolation kit (Sigma-Aldrich, St. Louis, MO, USA), and PCR amplification of the 16S rRNA gene was done using the universal primers 8-27F (5'-AGAGTTTGATCCTGGCTCAG$\left.3^{\prime}\right)$ and 1492R (5'-TACGTTACCTTGTTACGACTT3 '). Sanger's dideoxy sequencing method was used in sequence determination of $16 \mathrm{~S}$ rRNA gene of the bacterium. The 16S rRNA gene sequence was then identified using the GenBank database at NCBI. A phylogenetic tree was constructed using the MEGA X software.

\section{Characterization of KMT-4 for plant growth-promoting traits}

The bacterium was screened for the presence of various direct as well as indirect growth-promoting attributes like IAA production, ammonia excretion, phosphate solubilization, chitinase activity, siderophore production, and hydrogen cyanide production. Three replicates were used for each experiment. KMT-4 was tested for quantitative estimation of IAA production and ammonia excretion in the culture supernatant by the method given by Tang and Bonner (1974) and Chaney and Marbach (1962), respectively. Phosphate solubilization activity was checked by the ability to form a zone around the bacterial spots on Pikovskaya agar plates supplemented with tricalcium phosphate (Pikovskaya, 1948). Similarly, chitinase activity was determined by spot test method on colloidal chitin agar plates (Murthy and Bleakley, 2012). A hollow zone formation around the spots indicated chitinase activity. Siderophore production was detected by CAS (Chrome Azurol S) assay (modified method of Schwyn and Neilands, 1987). The presence of iron chelating compounds (siderophores) was depicted by the decolorization of the blue-colored ferric dye complex, giving yellow hollow zone around the bacterial colonies. For $\mathrm{HCN}$ production, the bacterium was transferred to test tubes containing freshly prepared King's B medium amended with glycine and sterile filter paper strips saturated with picric acid solution fixed inside. Change of 
color from yellow to reddish brown indicated cyanogenic potential (Alstrom and Burns, 1989).

\section{Collection of nematodes}

Meloidogyne javanica was cultured on brinjal and tomato plants under greenhouse conditions in Hisar, India. The infected roots were collected and rinsed with tap water after that dipped in $0.4 \%$ sodium hypochlorite $(\mathrm{NaClO})$ solution (Hussey and Barker, 1973) and again rinsed for $5 \mathrm{~min}$. The eggs thus released from egg masses on roots were concentrated on a 500-mesh sieve and rinsed with tap water. Juveniles (J2) were obtained from eggs after incubating them in distilled water at $25^{\circ} \mathrm{C}$ and collected by using modified Baermann funnel technique (MBFT) (Viglierchio and Schmitt, 1983) after $48 \mathrm{~h}$. The number of $\mathrm{J} 2$ was standardized by counting them in $1 \mathrm{ml}$ suspension; average number was used to represent the number of $\mathrm{J} 2 / \mathrm{ml}$. Egg masses were picked using a hand lens.

\section{Effect of KMT-4 on hatching of egg masses and juvenile mortality in vitro}

KMT-4 culture broth was grown for $72 \mathrm{~h}$ and centrifuged at a speed of 10,000 rpm for $10 \mathrm{~min}$. The supernatant thus obtained was used as extracellular extract, and the bacterial pellet was dissolved in a $0.1 \mathrm{M}$ phosphate buffer of $\mathrm{pH} 7$ for preparing the intracellular extract. The bacterial cells were ruptured using freezing and thawing technique (Harrison, 2011) and centrifuged at $10,000 \mathrm{rpm}$ for $10 \mathrm{~min}$. The supernatant obtained was used as intracellular extract, and the pellet thus formed was then discarded. Egg masses were collected from nematode $M$. javanica-infected brinjal roots using forceps and hand lens. Five egg masses (with a mean no. of 225 eggs) were added to $5 \mathrm{ml}$ of each-untreated distilled water (control), extracellular extract, intracellular extract, and intact bacterial suspension $(72 \mathrm{~h}$ grown culture broth) of the bacterial isolate in a 6-well culture plate. Hatching was observed at an interval of 24 till 96 h. The number of juveniles (J2) observed was recorded and compared with control. The number of $\mathrm{J} 2$ in suspension was standardized by counting them in $1 \mathrm{ml}$ suspension; the average number was used to represent the number of $\mathrm{J} 2 / \mathrm{ml}$. Nematode suspension containing 100 $\mathrm{J} 2$ was treated by the bacterial isolate. The number of dead J2 was recorded till $48 \mathrm{~h}$ if their bodies were stiff and straight by pricking them with a needle. The mortality percentage was calculated using the following equation:

[(live J2 prior to treatment-live J2 after $48 \mathrm{~h}$ )/live J2 prior to treatment] $\times 100$

A stereo microscope was used to observe the nematodes. All the experiments were conducted in 3 replicates. Phosphate buffer and growth medium were also used as control.

\section{Pot house experiment on brinjal}

To evaluate the effect of KMT-4 for biological control of $M$. javanica and growth promotion of host plant, an experiment was conducted on brinjal (Solanum melongena L.) in the pot house of Department of Microbiology, Hisar. Five kilograms sandy loam soil was used to fill up the clay pots of 8 -in. diameter, and a recommended dose of fertilizers (RDF) consisting of slurry $10^{4} \mathrm{~kg} / \mathrm{ha}$, urea $40 \mathrm{~kg} / \mathrm{ha}$, single superphosphate (SSP) $20 \mathrm{~kg} / \mathrm{ha}$, and muriate of potash (MoP) $10 \mathrm{~kg} / \mathrm{ha}$ was applied to each pot. Seedlings of nematode-susceptible brinjal var. BR112 (obtained from the Department of Vegetable Science, Hisar) at 2-leaf stage were transplanted into the pots. A total of six treatments were used for the pot experiment as T1, control (RDF); T2, RDF + Azotobacter chroococcum Mac27 $\left(10^{8} \mathrm{CFU} / \mathrm{ml}\right)$; T3, $\mathrm{RDF}+$ M. javanica; $\mathrm{T} 4, \mathrm{RDF}+$ M. javanica + A. chroococcum Mac27 $\left(10^{8} \mathrm{CFU} / \mathrm{ml}\right) ; \mathrm{T} 5, \mathrm{RDF}+$ M. javanica + carbofuran at 1 $\mathrm{kg}$ a.i/ha; and T6, RDF + M. javanica + isolate KMT-4 $\left(10^{8} \mathrm{CFU} / \mathrm{ml}\right)$. Seedlings were treated with $50 \mathrm{ml} \mathrm{KMT}-4$ $\left(10^{8} \mathrm{CFU} / \mathrm{ml}\right)$ and $50 \mathrm{ml}$ A. chroococcum Mac27 $\left(10^{8}\right.$ $\mathrm{CFU} / \mathrm{ml}$ obtained from the collection of Department of Microbiology, Hisar, Haryana), and carbofuran @ 1kg a.i/ha was added as per treatments described above. $A$. chroococcum Mac27 was referred to as plant growth control and carbofuran as chemical control. Plants were irrigated by tap water regularly. After 10 days of transplantation, nematode suspension containing eggs at 3000 eggs/pot was injected in the rhizosphere of plants with the help of a pipette in four 1-cm deep holes around the roots. There were 3 replicates of each treatment. The pot experiment was organized in a completely randomized design. Crop was uprooted after 45 days, and observations on number of eggs/root system, no. of galls/root system, and final nematode population/200cc soil were recorded. No. of eggs/root system was isolated by dipping the roots in $0.4 \% \mathrm{NaClO}$ with stirring for 5 min and counted under stereomicroscope. The number of galls/root system was counted with the help of hand lens by spreading the roots in a $15-\mathrm{cm}$ wide Petri plate. For determining final nematode population, soil from each treatment was mixed thoroughly, and $200 \mathrm{cc}$ soil from each replicate was analyzed by Cobb's sieving and decanting method (Cobb, 1918), followed by MBFT. Obtained J2 were counted under stereomicroscope. Plant growth parameters like plant height, root fresh weight, root dry weight, shoot fresh weight, and shoot dry weight were also recorded on the 45th day of transplanting. Total bacterial populations were determined from the rhizosphere both at 0 and after 45 days of treatment. 


\section{Field trials}

Field trials were conducted separately during the year 2018 and 2019 on brinjal (Solanum melongena L.) and cucumber (Cucumis sativus L.) crops, respectively to check the efficacy of the bacterial isolate KMT-4 under protected cultivation at farmer's polyhouse in Bhuna (Fatehabad), Haryana, India (29 $32^{\prime} 17.0412^{\prime \prime} \mathrm{N}, 75^{\circ} 42^{\prime}$ $28.9368^{\prime \prime} \mathrm{E}$ ) with initial nematode population of $275 \mathrm{~J} 2 /$ 200cc of soil. Brinjal var. Hisar Shyamal and cucumber var. Multistar were selected for the experiment. A total of 3 treatments including control (water), KMT-4, and chemical carbofuran at $1 \mathrm{~kg}$ a.i./ha were incorporated. Brinjal seedlings (at two leaf stage) were dipped in KMT-4 broth $\left(10^{8} \mathrm{CFU} / \mathrm{ml}\right)$ for $30 \mathrm{~min}$ before transplantation, and cucumber seeds were coated with $50 \mathrm{~g}$ jaggary suspension after that mixed with $100 \mathrm{ml}$ of KMT-4 broth $\left(10^{8} \mathrm{CFU} / \mathrm{ml}\right)$, partially dried then sown into the field. The field experiment was arranged as a randomized block design with 6 replicate plots of each treatment. Plot size was $6 \times 4 \mathrm{~m}$. Roots from these plants were indexed for galling and egg masses on a scale of 15 (Heald et al., 1989). For the estimation of final nematode population, Cobb's sieving and decanting method (Cobb, 1918) was used, followed by MBFT. The extracted J2 were counted at $\times 40$ magnification under a stereomicroscope. Yield ( $\mathrm{q} / \mathrm{ha}$ ) was determined after harvest. All the data were statistically analyzed and compared with control as well as chemically treated plants.

\section{Data analysis}

All the given values are expressed as mean \pm standard error (SE). The SAS version 9.2 software (SAS Institute, Inc.) was used for all the statistical analysis. Means were separated and compared using Duncan's multiple range test. Differences in mean values were considered significant when $P<0.05$.

\section{Results}

\section{Bacterial identification}

Based on morphological studies, it was found that the strain KMT-4 grown on King's B medium has round, creamy-white colony morphology with regular edges. The bacterium was Gram positive, and the cells were rod shaped. The $16 \mathrm{~S}$ rRNA gene analysis showed that a 350-bp fragment was amplified by the primers 27F/ 1492R from the genomic DNA of KMT-4. KMT-4 had $100 \%$ similarity to Bacillus aryabhattai as per data of GenBank. The phylogenetic tree was constructed by maximum likelihood method, using MEGA X from related sequences of Bacillus species downloaded from NCBI; KMT-4 was most closely related to B. aryabhattai (Fig. 1). According to all the morphological studies and molecular biology experiments, KMT-4 was identified as B. aryabhattai. The $16 \mathrm{~s}$ rRNA sequence of the bacterium $B$. aryabhattai KMT-4 was then submitted to the GenBank database. The accession number obtained was MT620775.

\section{Plant growth-promoting attributes of KMT-4}

KMT-4 bacterial isolate was characterized for various plant growth-promoting traits. The bacterium showed significant siderophore production by forming a 3-mm yellow zone around the colony. A 2-mm hollow zone was formed around the bacterial colony on chitin agar plate showing chitinase activity exhibited by KMT-4. The filter paper strips turned light brown in color indicating HCN production by the bacterium when observed after $96 \mathrm{~h}$ of incubation at $28^{\circ} \mathrm{C}$. Ammonia excretion and IAA production were recorded quantitatively as $2.0 \pm 0.0 \mu \mathrm{g} / \mathrm{ml}$ and $18.7 \pm 0.0 \mu \mathrm{g} / \mathrm{ml}$, respectively. No phosphate solubilization activity was exhibited by the bacterium.

\section{Hatching and mortality test of KMT-4 against $M$. javanica in vitro}

In vitro studies showed that KMT-4 has antagonistic activity against $M$. javanica. Hatching in egg masses was observed at a regular interval of $24 \mathrm{~h}$ till $96 \mathrm{~h}$. A considerable difference was found between the number of hatched juveniles (J2) in KMT-4 treatment as compared to control. The number of hatched J2 in the extracellular extract was least than the control and intracellular extract, while at par in intact bacterial suspension after 96 h (Table 1). Also, a similar trend was observed during the mortality test. KMT-4 resulted in $86.33 \%$ mortality after $48 \mathrm{~h}$, while in control it was $4.33 \%$ showing a significant difference between the two.

\section{Biocontrol of $M$. javanica in pot experiments on brinjal}

During pot house studies on brinjal, it was found that the least number of galls was observed in KMT-4inoculated plant than the control and chemically treated plant, i.e., carbofuran treatment. Similarly, up to $73 \%$ decline in egg number was observed in KMT-4 inoculatedplant roots (T6) as compared to control (T3), where it was only 5.8 and $55 \%$ in chemical treatment (T5). After 45 days, when nematode population per 200cc soil was counted, there was a significant difference in number of juveniles observed between KMT-4 treatment, control, and chemical carbofuran treatment. Based on all these observations, KMT-4 inoculation was found most effective in controlling nematode $M$. javanica (Table 2).

\section{Effect of KMT-4 on plant growth and yield in pot as well as field experiments}

The effect of KMT-4 on plant growth as well as yield was also observed. KMT-4 inoculation resulted in maximum plant height and highest fresh and dry weight of 


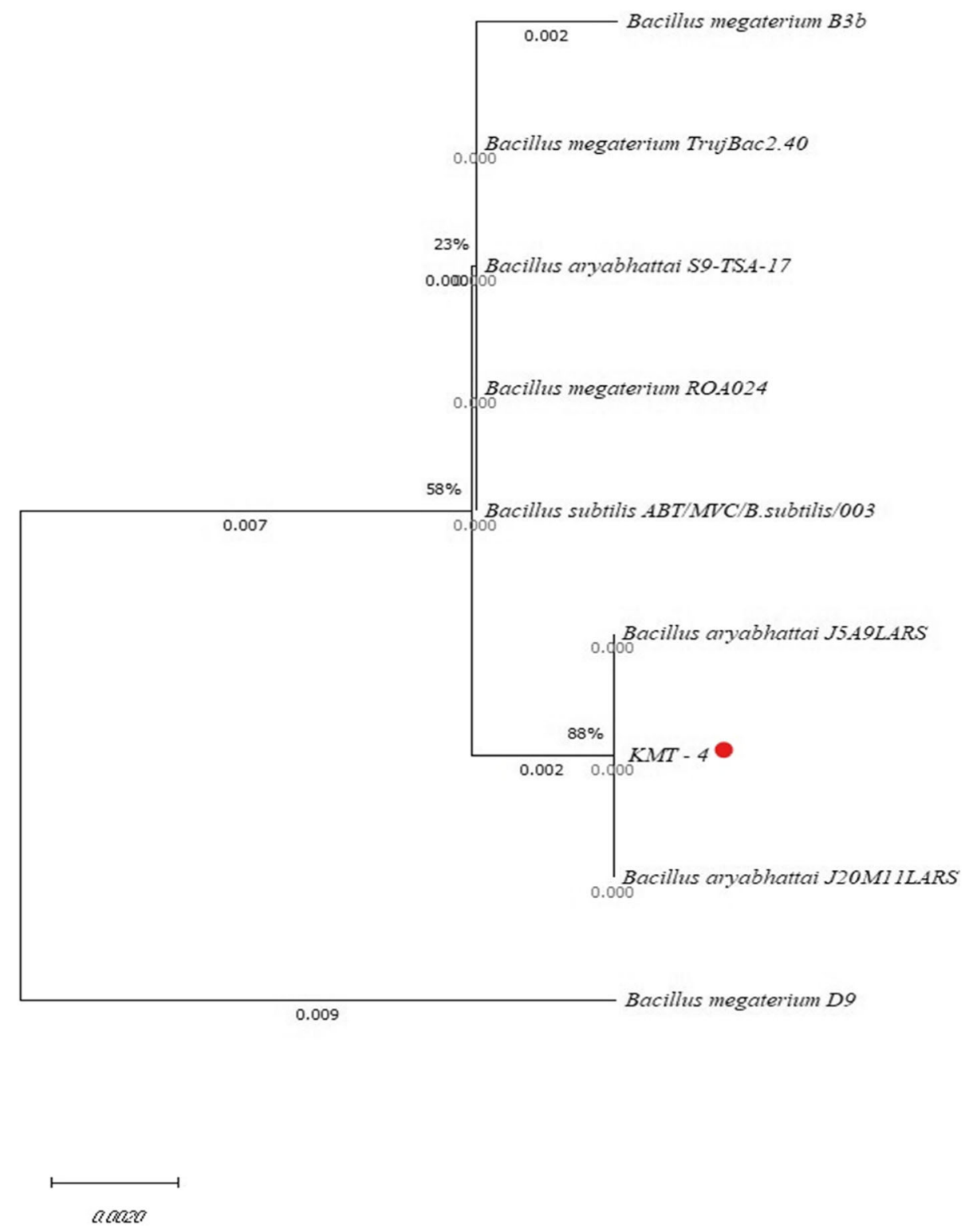

Fig. 1 Phylogenetic tree of Bacillus species based on analysis of the 16S rRNA gene sequences constructed by Maximum Likelihood method using MEGA X

Table 1 Effect of Bacillus aryabhattai KMT-4 on hatchability of eggs masses of M. javanica in vitro

\begin{tabular}{|c|c|c|c|c|}
\hline \multirow[t]{2}{*}{ Treatment } & \multicolumn{4}{|c|}{ Hatchability $^{\wedge}$} \\
\hline & $24 \mathrm{~h}$ & $48 \mathrm{~h}$ & $72 \mathrm{~h}$ & $96 \mathrm{~h}$ \\
\hline Distilled water & $21.3 \pm 0.8^{\mathrm{AB}}$ & $38.6 \pm 0.8^{A}$ & $77.3 \pm 1.2^{\mathrm{A}}$ & $102.6 \pm 1.4^{A}$ \\
\hline Phosphate buffer ${ }^{\#}$ & $19.3 \pm 0.8^{B}$ & $39.0 \pm 0.5^{\mathrm{A}}$ & $74.3 \pm 1.4^{\mathrm{A}}$ & $101.6 \pm 2.1^{\mathrm{A}}$ \\
\hline King's B broth & $21.6 \pm 0.8^{\mathrm{A}}$ & $39.0 \pm 1.1^{\mathrm{A}}$ & $75.6 \pm 1.7^{\mathrm{A}}$ & $102.6 \pm 0.8^{A}$ \\
\hline Intact bacterium & $0.6 \pm 0.3^{\mathrm{D}}$ & $2.3 \pm 0.3^{C}$ & $5.6 \pm 0.3^{C}$ & $7.0 \pm 5.7^{\mathrm{BC}}$ \\
\hline Extracellular extract & $0.6 \pm 0.3^{D}$ & $3.0 \pm 0.5^{\complement}$ & $3.6 \pm 0.6^{C}$ & $4.6 \pm 0.6^{C}$ \\
\hline Intracellular extract & $5.6 \pm 0.3^{C}$ & $7.6 \pm 0.3^{B}$ & $10.0 \pm 0.5^{\mathrm{B}}$ & $10.6 \pm 0.8^{B}$ \\
\hline
\end{tabular}

\#0.1 M, pH 7, values are depicting number of hatched $\mathrm{J} 2$

${ }^{\wedge}$ Data presented are the mean \pm standard error (SE) for 3 replicates of each treatment. Values with the same letter in the same column are not statistically significant using Duncan's multiple range test $(p<0.05)$ both root and shoot as compared to all other treatments including control, $A$. chroococcum Mac27 treatment, and carbofuran treatment in the pot experiments (Table 3 ) (Fig. 2). In the field studies, yield (q/ha) also increased significantly in case of KMT-4-inoculated plants than the control and chemically treated ones in both the field trials on brinjal and cucumber crops during 2018 and 2019 (Table 4).

\section{Efficacy of KMT-4 in biocontrol of nematodes under field conditions}

During the field trials on brinjal and cucumber crops in the year 2018 and 2019 respectively, the root-knot index 
Table 2 Effect of Bacillus aryabhattai KMT-4 on nematode population after 45 days of treatment in pot experiment on brinjal (Solanum melongena L.)

\begin{tabular}{llll}
\hline Treatment $^{\#}$ & Numbers of galls/root system $^{\wedge}$ & Numbers of eggs/root system $^{\wedge}$ & Final $^{\text {nematode population/200cc soil }}{ }^{\wedge}$ \\
\hline T1 & - & - & - \\
T2 & - & - & - \\
T3 & $31.6 \pm 2.3^{\mathrm{A}}$ & $2826.6 \pm 92.0^{\mathrm{A}}$ & $1141.6 \pm 18.0^{\mathrm{A}}$ \\
$\mathrm{T} 4$ & $26.0 \pm 2.5^{\mathrm{B}}$ & $2153.3 \pm 269.0$ & $308.0 \pm 6.0^{\mathrm{B}}$ \\
T5 & $13.0 \pm 1.5^{\mathrm{C}}$ & $1336.6 \pm 64.3^{\mathrm{C}}$ & $267.3 \pm 3.7^{\mathrm{C}}$ \\
T6 & $6.3 \pm 1.7^{\mathrm{D}}$ & $813.3 \pm 70.5^{\mathrm{D}}$ & $108.0 \pm 1.5^{\mathrm{D}}$ \\
\hline
\end{tabular}

T1 and T2 were not inoculated with nematode $M$. javanica according to the treatment plan, and initially, there were 3000eggs/root system. (T3, RDF + M. javanica; $\mathrm{T} 4, \mathrm{RDF}+$ M. javanica + A. chroococcum Mac27 $\left(10^{8} \mathrm{CFU} / \mathrm{ml}\right) ; \mathrm{T} 5, \mathrm{RDF}+$ M. javanica + Carbofuran at $1 \mathrm{~kg}$ a.i/ha; and T6, RDF + M. javanica + isolate KMT-4 $\left(10^{8} \mathrm{CFU} / \mathrm{ml}\right)$

${ }^{\wedge}$ Data presented are the mean \pm SE for three replicates of each treatment. Values with the same letter in the same column are not statistically significant using Duncan's multiple range test $(p<0.05)$

was the same in both trials in KMT-4-inoculated plants, also significantly different from both control as well as chemical nematicide carbofuran treatment $(1 \mathrm{~kg}$ a.i./ha). Initial nematode population was 275 J2/ 200cc soil. Final nematode population per 200cc soil was significantly reduced in KMT-4 treatment on brinjal and cucumber crop trials when compared with control and carbofuran treatments. There was a significant difference in all the observations paving a way to KMT-4 treatment as a better method of nematode control at field levels (Table 4).

\section{Discussion}

The most common damage-causing nematodes through their plant-parasitic interactions in crops are the rootknot nematodes (Meloidogyne spp.). The conventional methods used to control plant-parasitic nematodes in agricultural systems are currently dependent on use of chemicals. Many chemicals recommended for nematode control such as carbofuran, carbosulfan, chloropicrin, and ethylene dibromide are being banned in various countries. In the last decade, many scientific studies have reported the success of effective control of Meloidogyne species using rhizospheric bacteria (Doaa et al. 2021). In the present investigation, bacterial isolate KMT-4 was isolated from nematode-infested soil of the tomato rhizosphere and was reported as $B$. aryabhattai based on morphological studies and 16S rRNA sequencing. Many bacterial species have been isolated from rhizospheric soils and identified using 16S rRNA sequencing. The first report of isolation of this bacterial species was from the cryotubes used for air collection from the upper atmosphere (Shivaji et al., 2009), and it was later on obtained from rhizosphere soils (Lee et al., 2012).

In the present case, the bacterium $B$. aryabhattai KMT-4 showed IAA production and ammonia excretion during in vitro experiments, which can be attributed to its plant growth-promoting properties. The mechanism of action of plant growth-promoting rhizosphere bacteria (PGPR) strains mainly includes increased nutrient availability, phytohormone production, and inducing systemic resistance. Rhizospheric bacterial isolates are more efficient in IAA production than the isolates from bulk soil and are associated with increased plant growth. The production of ammonia as a common trait of PGPR has also been reported (Raghavan et al., 2015).

The bacterium KMT-4 was tested for antagonistic activity against the nematode $M$. javanica. In vitro studies showed that extracellular extract resulted in minimum

Table 3 Effect of Bacillus aryabhattai KMT-4 on plant growth after 45 days of treatment in pot experiments on brinjal (Solanum melongena L.)

\begin{tabular}{|c|c|c|c|c|c|}
\hline Treatment $^{\#}$ & Plant height $(\mathrm{cm})^{\wedge}$ & Root fresh weight $(\mathrm{g})^{\wedge}$ & Root dry weight $(g)^{\wedge}$ & ${\text { Shoot fresh weight }(\mathbf{g})^{\wedge}}^{\wedge}$ & Shoot dry weight $(g)^{\wedge}$ \\
\hline $\mathrm{T1}$ & $6.5 \pm 0.7^{C}$ & $0.4 \pm 0.1^{\mathrm{D}}$ & $0.08 \pm 0.0^{C}$ & $0.8 \pm 0.0^{C}$ & $0.1 \pm 0.0^{C}$ \\
\hline $\mathrm{T} 2$ & $7.6 \pm 0.3^{c}$ & $0.7 \pm 0.1^{\mathrm{D}}$ & $0.13 \pm 0.0^{B C}$ & $1.9 \pm 0.3^{\mathrm{BC}}$ & $0.3 \pm 0.0^{B C}$ \\
\hline T3 & $10.3 \pm 0.8^{B}$ & $2.9 \pm 0.3^{C}$ & $0.19 \pm 0.0^{B C}$ & $2.6 \pm 0.5^{B}$ & $0.3 \pm 0.0^{B C}$ \\
\hline T4 & $10.5 \pm 0.7^{B}$ & $4.3 \pm 0.5^{\mathrm{B}}$ & $0.21 \pm 0.0^{B}$ & $1.9 \pm 0.5^{\mathrm{BC}}$ & $0.5 \pm 0.0^{B}$ \\
\hline T5 & $10.6 \pm 0.8^{B}$ & $2.5 \pm 0.2^{c}$ & $0.18 \pm 0.0^{B C}$ & $2.1 \pm 0.4^{\mathrm{BC}}$ & $0.3 \pm 0.1^{\mathrm{BC}}$ \\
\hline T6 & $15.3 \pm 0.8^{\mathrm{A}}$ & $8.3 \pm 0.7^{\mathrm{A}}$ & $1.19 \pm 0.0^{\mathrm{A}}$ & $7.2 \pm 0.5^{\mathrm{A}}$ & $1.6 \pm 0.2^{\mathrm{A}}$ \\
\hline
\end{tabular}

"Treatment-T1, control (RDF); T2, RDF + A. chroococcum Mac27 (10 CFU/ml); T3, RDF + M. javanica; T4, RDF + M. javanica + A. chroococcum Mac27 (10 $\left.{ }^{8} \mathrm{CFU} / \mathrm{ml}\right) ;$ $\mathrm{T} 5, \mathrm{RDF}+M$. javanica + carbofuran at $1 \mathrm{~kg}$ a. $/ \mathrm{ha}$; and T6, RDF + M. javanica + isolate KMT-4 $\left(10^{8} \mathrm{CFU} / \mathrm{ml}\right)$

${ }^{\wedge}$ Data presented are the mean \pm SE for three replicates of each treatment. Values with the same letter in the same column are not statistically significant using Duncan's multiple range test $(p<0.05)$ 


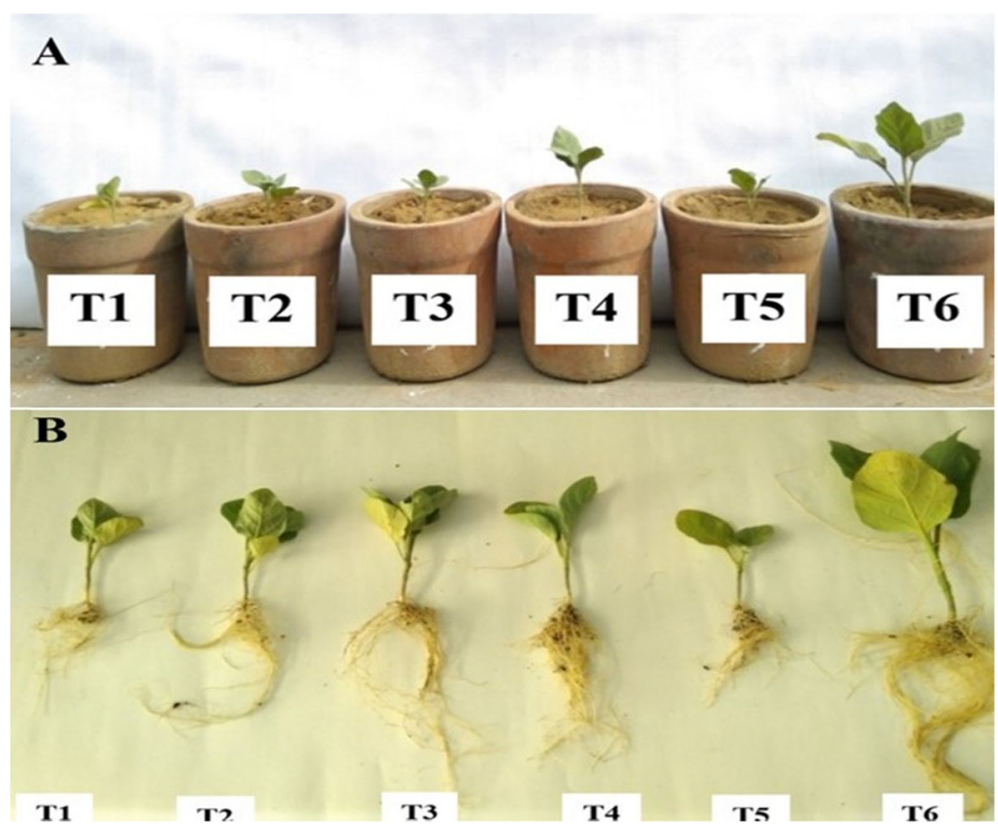

Fig. 2 Comparative plant growth in Bacillus aryabhattai KMT-4 treatment (T6) with T1, T2, T3, T4, and T5 (a in pots, b after harvest) during the pot house experiment on brinjal (Solanum melongena L.) crop

hatching in egg masses than the intact bacterial suspension and intracellular extract. It could be inferred that some secondary metabolite may be responsible for such nematicidal activity. The bacterium KMT-4 showed siderophore production, chitinase activity as well as hydrogen cyanide production during in vitro studies. This can be correlated to the nematicidal activity exhibited by the bacterium against $M$. javanica. A vast variety of PGPR has been investigated and explored for their ability of being used as effective biological control agents against phyto-pathogenic nematodes (Migunova and Sasanelli, 2021). The application of rhizospheric microorganisms (Azotobacter chroococcum, Bacillus subtilis, and Trichoderma harzianum) and their combinations reduced the average no. of galls, immature stages, juveniles (J2), and final population of nematode in brinjal (Farfour and ElAnsary, 2013). Biocontrol activity was normally associated with production of secondary metabolites such as enzymes, toxic volatile compounds, antibiotics, or certain chelating agents like siderophores. Jenifer et al. (2013) reported that rhizospheric strains of Pseudomonas, Azotobacter, and Bacillus were capable of producing siderophores, which acted as biocontrol agent and efficiently inhibited phytopathogens like Fusarium sp., Alternaria sp., and Sclerotium sp. Chitinase degrades chitin which is the structural material in cell walls of fungal pathogens, the eggs of nematodes, and also in nematode egg masses. Bacillus cereus 1.21 strain isolated from chilli rhizosphere was reported to show its biocontrol potential against white fly due to its chitinolytic properties (Mubarik et al., 2010). Hydrogen cyanide is a volatile compound synthesized as a consequence of secondary metabolism of several microorganisms. It causes fatal effects on the growth of other organisms. It

Table 4 Effect of inoculation of Bacillus aryabhattai KMT-4 at farmer's polyhouse at Bhuna (Fatehabad) on brinjal (Solanum melongena L.) and cucumber (Cucumis sativus L.) crops during the year 2018 and 2019, respectively

\begin{tabular}{|c|c|c|c|c|c|c|}
\hline \multirow[t]{2}{*}{ Treatment } & \multicolumn{2}{|c|}{ Root knot index $(\mathrm{RKI})^{\wedge a}$} & \multicolumn{2}{|c|}{ Final nematode population $/ 200 \mathrm{cc}$ soil $^{\wedge b}$} & \multicolumn{2}{|c|}{${\text { Yield }(q / h a)^{\wedge}}^{\wedge}$} \\
\hline & Brinjal & Cucumber & Brinjal & Cucumber & Brinjal & Cucumber \\
\hline KMT-4 & $2.0 \pm 0.0^{C}$ & $2.0 \pm 0.0^{C}$ & $171.5 \pm 0.6^{C}$ & $117.6 \pm 0.6^{C}$ & $3.1 \pm 0.0^{\mathrm{A}}$ & $96.0 \pm 0.9^{\mathrm{A}}$ \\
\hline Carbofuranc & $3.0 \pm 0.0^{\mathrm{B}}$ & $3.0 \pm 0.0^{\mathrm{B}}$ & $260.8 \pm 0.9^{B}$ & $230.8 \pm 0.9^{B}$ & $2.5 \pm 0.0^{B}$ & $91.0 \pm 1.0^{\mathrm{B}}$ \\
\hline Control & $5.0 \pm 0.0^{\mathrm{A}}$ & $5.0 \pm 0.0^{\mathrm{A}}$ & $406.5 \pm 1.5^{\mathrm{A}}$ & $490.0 \pm 1.1^{\mathrm{A}}$ & $2.3 \pm 0.0^{B}$ & $84.5 \pm 0.5^{c}$ \\
\hline
\end{tabular}

${ }^{a}$ Root knot index, 1 = no gall and egg-mass (highly resistant), $2=1-2$ galls/egg-mass (resistant), $3=11-30$ galls/egg-mass (moderately resistant), $4=31-100$ galls/egg-mass (susceptible), and $5=101$ and above (highly susceptible) (Heald et al. 1989).

Initial nematode population was $275 \mathrm{~J} 2 / 200 \mathrm{cc}$ soil

${ }^{c}$ Carbofuran at $1 \mathrm{~kg}$ a.i./ha.

${ }^{\wedge}$ Data presented are the mean \pm SE for 6 replicates of each treatment of the field trials separately conducted in 2018 and 2019 on brinjal and cucumber crops, respectively. Values with the same letter in the same column are not statistically significant using Duncan's multiple range test $(p<0.05)$ 
effectively stops the cytochrome oxidase reaction and is lethal to all the pathogenic aerobic microbes even in picomolar amounts (Hassanein et al., 2009). Kang et al. (2018) reported HCN production by Pseudomonas chlororaphis O6, which results in its nematicidal activity against $M$. hapla. However, it can be assumed that the decline in galling and formation of egg masses by $M$. javanica might be due to the direct action of secondary metabolites, which caused harm to the nematodes (J2), or the indirect effects that elicit host defense response to protect from nematode infection, as reported in the PGPR Paenibacillus strains (Son et al., 2009).

Observations from both pot as well as field studies showed that KMT-4 strain efficiently reduced egg hatching and increased mortality of juveniles in soil. Similarly, Zhao et al. (2019) reported biocontrol potential of $B$. aryabhattai strain Sneb517 against soybean cyst nematode Heterodera glycines. During the pot experiment, parameters representing plant growth were noted after 45 days of sowing. Effect of KMT-4 on plant height was observed at the time of harvest being made after 45 days. Under pot house conditions, a considerable increase was observed in fresh and dry weights of both root and shoot in KMT-4 treatment than the control and also Azotobacter chroococcum Mac 27 strain treatment. During field studies on brinjal and cucumber, a similar trend in plant growth was observed along with decreased nematode infection. In the field experiments, a considerable increase in yield was observed than the control and chemical nematicide treatment, which represents nematode suppression along with enhanced plant growth due to KMT-4 inoculation. Many researchers have reported results showing that the application of chemical nematicides resulted in better growth of plants and decrease in nematode infection. The chemical control carbofuran has been reported to show visible increase in all morphological observations and reduced galls in roots and population of nematodes (Jena et al., 2017). Patil et al. (2013) also reported the maximum decrease in nematode population with chemical carbosulfan treatment. But, in the present study, it was found that KMT-4 treatment showed a maximum growth and effectively reduced infection than the chemical control carbofuran itself. There is a limited number of such strains which can act as both biocontrol agents and a plant growth promoter simultaneously. This study is among the first reports on $B$. aryabhattai strain that can efficiently control nematode infection along with promoting plant growth and resulted in better yield as compared to other plant growth promoters and chemical fertilizers.

\section{Conclusion}

The treatment of seedlings with $B$. aryabhattai KMT-4 strain significantly reduced nematode infection in both pot and field experiments along with improving plant growth and yield. In vitro studies also showed hatching inhibition and juvenile mortality. This proves that $B$. aryabhattai KMT-4 may serve as a potent biocontrol agent as well as an efficient plant growth promoter. A combination of two or more mechanisms may be responsible for the biological control of $M$. javanica, as exhibited by the PGPR used in this study. Also, there could be any other mechanism involved, which has not been covered in this study and requires different scientific approaches.

\section{Abbreviations}

CFU: Colony-forming unit; HCN: Hydrogen cyanide; IAA: Indole acetic acid; MBFT: Modified Baermann Funnel Technique; NCBI: National Center for Biotechnology Information; PCR: Polymerase chain reaction; PGPR: Plant growth-promoting rhizospheric bacteria; RDF: Recommended dose of fertilizers

\section{Acknowledgements}

This entire work was done in the Department of Microbiology and Department of Nematology, CCS HAU, Hisar, Haryana. Field trials were conducted at local farmer's fields. No outside funding agency was involved.

\section{Authors' contributions}

SA conducted the experiments, interpreted the data, and prepared and wrote the manuscript. RK conceptualized the study. RK, DVP, and AKV provided the resources. AP performed bioinformatical analysis. SA and AK edited the manuscript. VK monitored the field experiments. All authors read and approved the final manuscript.

\section{Funding}

The authors did not receive support from any organization for the submitted work.

Availability of data and materials

All the data that support the findings of this study are available in the manuscript.

\section{Declarations}

Ethics approval and consent to participate

This paper does not contain any studies with human participants or animals performed by any of the authors.

\section{Consent for publication}

Not applicable

\section{Competing interests}

The authors declare that they have no competing interests.

\section{Author details}

${ }^{1}$ Department of Microbiology, College of Basic Sciences and Humanities, CCS Haryana Agricultural University, Hisar, Haryana 125004, India. ${ }^{2}$ Department of Nematology, College of Agriculture, CCS Haryana Agricultural University, Hisar, Haryana 125004, India. ${ }^{3}$ Department of Molecular Biology, Biotechnology and Bioinformatics, College of Basic Sciences and Humanities, CCS Haryana Agricultural University, Hisar, Haryana 125004, India. ${ }^{4}$ Centre of Food Science and Technology, CCS Haryana Agricultural University, Hisar, Haryana 125004, India.

Received: 5 February 2021 Accepted: 11 April 2021

Published online: 20 April 2021

\section{References}

Alstrom S, Burns RG (1989) Cyanide production by rhizobacteria as a possible mechanism of plant growth inhibition. Biol Fertil Soils 7(3):232-238. https:// doi.org/10.1007/BF00709654 
Chaney AL, Marbach EP (1962) Method for evaluating biological nitrogen fixation. Clin Chem 8(2):130-132. https://doi.org/10.1093/clinchem/8.2.130

Cobb NA (1918) Estimating the nema populations of soil. USDA Tech Circ 1:48

Doaa K, Refaei AR, Mostafa FAM (2021) Management of Meloidogyne incognita infecting eggplant using moringa extracts, vermicompost, and two commercial bio-products. Egypt J Agron 20(1):1-16

FAO (2014). FAOSTAT production databases. Available online at: http://www.fa ostat.fao.org

Farfour SA, El-Ansary MSM (2013) Suppression of root-knot nematode (Meloidogyne incognita) on eggplant by applying some biofertilizers and biocontrol agents. Egypt J Agron 12(1):63-73

Harrison STL (2011) Engineering fundamentals of biotechnology. Comprehensive Biotechnology, 2nd edition

Hassanein WA, Awny NM, El-Mougith AA, El-Dein SH (2009) Characterization and antagonistic activities of metabolite produced by P. aeruginosa Sha8. J. Appl. Sci. Res. 5(4):392-403

Heald CM, Bruton BD, Davis RM (1989) Influence of Glomus intradices and soil phosphorus on M. incognita infecting Cucumis melo. J Nematol 21(1):69-73

Hussey RS, Barker KR (1973) A comparison of methods of collecting inocula of Meloidogyne spp. including a new technique. Plant Dis Rep 57:1025-1028

Jamal Q, Cho JY, Moon JH, Munir S, Anees M, Kim KY (2017) Identification for the first time of Cyclo(D-Pro-L-Leu) produced by Bacillus amyloliquefaciens Y1 as a nematocide for control of Meloidogyne incognita. Molecules 22(11):1839. https://doi.org/10.3390/molecules22111839

Jena R, Basumatary B, Mohanta B, Pradhan SR (2017) Comparative efficacy of bio control agents against root knot nematode (Meloidogyne incognita) infecting brinjal. J Entomol Zool Stud 5(6):254-257

Jenifer MRA, Reena A, Aysha OS, Valli S, Nirmala P, Kumar PV (2013) Isolation of siderophore producing bacteria from rhizosphere soil and their antagonistic activity against selected fungal plant pathogens. Int J Curr Microbiol App Sci 2:59-65

Kang BR, Anderson AJ, Kim YC (2018) Hydrogen cyanide produced by Pseudomonas chlororaphis $\mathrm{O6}$ exhibits nematicidal activity against Meloidogyne hapla. Plant Pathol J 34(1):35-43. https://doi.org/10.5423/PPJ.OA. 06.2017 .0115

King EO, Ward MK, Raney DE (1954) Two simple media for the demonstration of pyocyanin and fluorescin. J Lab Clin Med 44(2):301-307. https://doi.org/10. 5555/uri:pii:002221435490222X

Lee S, Ka J, Song H (2012) Growth promotion of Xanthium italicum by application of rhizobacterial isolates of Bacillus aryabhattai in microcosm soil. J Microbiol 50(1):45-49. https://doi.org/10.1007/s12275-012-1415-z

Migunova VD, Sasanelli N (2021) Bacteria as biocontrol tool against phytoparasitic nematodes. Plants 10(2):389. https://doi.org/10.3390/plants10020389

Mohammed S, Saedy M, Enan M, Ibrahim NE, Ghareeb A, Moustafa S (2008) Biocontrol efficiency of Bacillus thuringiensis toxins against root-knot nematode, Meloidogyne incognita. Journal of Cell and Molecular Biology 7: $57-66$

Mubarik NR, Mahagiani I, Anindyaputri A, Santoso S, Rusmana I (2010) Chitinolytic bacteria isolated from chilli rhizosphere: chitinase characterization and its applications as biocontrol for whitefly (Bemisia tabaci Genn.). America J Agri Biol Sci 5(4):430-435

Murthy N, Bleakley B (2012) Simplified method of preparing colloidal chitin used for screening of chitinase-producing microorganisms. Intern J Microbiol 10(2):7

Patil J, Sharma MK, Bharvaga S, Srivastava AS (2013) Management of reniform nematode, Rotylenchulus reniformis on cowpea by using bio-agents and plant extracts. Indian J Nematol 242(2):167-171

Pikovskaya RI (1948) Mobilization of phosphorous in soil in connection with vital activity of some microbial species. Microbiol. 17:362-370

Raghavan D, Muthuswamy A, Aundy K, Yogiyar K, Binia K, Purayil S, Ravindran A (2015) Isolation, characterization, and evaluation of multi-trait plant growth promoting rhizobacteria for their growth promoting and disease suppressing effects on ginger. Microbiol Res 173:34-43. https://doi.org/10.1016/j.micres.2 015.01.014

Sahebani N, Hadavi N (2008) Biological control of the root-knot nematode Meloidogyne javanica by Trichoderma harzianum. Soil Biol Biochem 40(8): 2016-2220. https://doi.org/10.1016/j.soilbio.2008.03.011

Schwyn B, Neilands JB (1987) Universal chemical assay for the detection and determination of siderophores. Anal Biochem 160(1):47-56. https://doi.org/1 0.1016/0003-2697(87)90612-9
Shivaji S, Chaturvedi P, Begum Z, Pindi PK, Manorama R, Padmanaban DA, Shouche YS, Pawar S, Vaishampayan P, Dutt CBS, Datta GN, Manchanda RK, Rao UR, Bhargava PM, Narlikar JV (2009) Janibacter hoylei sp. nov., Bacillus isronensis sp. nov. and Bacillus aryabhattai sp. nov., isolated from cryotubes used for collecting air from the upper atmosphere. Int J Syst Evol Microbio 59(12):2977-2986. https://doi.org/10.1099/ijs.0.002527-0

Son SH, Khan Z, Kim SG, Kim YH (2009) Plant growth-promoting rhizobacteria, Paenibacillus polymyxa and Paenibacillus lentimorbus suppress disease complex caused by root-knot nematode and Fusarium wilt fungus. J Appl Microbiol 107:524-532. https://doi.org/10.1111/j.1365-2672.2009.04238.x

Tang YW, Bonner J (1974) The enzymatic activation of IAA. Some characteristics of the enzyme contained in pea seedlings. Arch Biochem Biophys 13:11-25

Viglierchio DR, Schmitt RV (1983) On the methodology of nematode extraction from field samples: Baermann funnel modifications. J Nematol 15(3):438-444

Zareena SK, Vanita Das W (2014) Root knot disease and its management in brinjal. Global J Biosci Technol 3(1):126-127

Zhang T, Li Y, Guo Y, Yan Y, He C, Yu X (2014) Effect of marigold intercropping density on the control of root-knot nematodes, growth and yield of cucumber. Chinese J Biol Cont 30

Zhao J, Liua D, Wang Y, Zhu X, Chen L, Duan Y (2019) Evaluation of Bacillus aryabhattai Sneb517 for control of Heterodera glycines in soybean. Biol Control 142:104147. https://doi.org/10.1016/j.biocontrol.2019.104147

\section{Publisher's Note}

Springer Nature remains neutral with regard to jurisdictional claims in published maps and institutional affiliations.

\section{Submit your manuscript to a SpringerOpen ${ }^{\circ}$ journal and benefit from:}

- Convenient online submission

- Rigorous peer review

- Open access: articles freely available online

- High visibility within the field

- Retaining the copyright to your article

Submit your next manuscript at $\boldsymbol{\nabla}$ springeropen.com 